\title{
FUNGSI LEMBAGA PEMASYARAKATAN DALAM MELAKSANAKAN PEMBINAAN TERHADAP WARGA BINAAN PEMASYARAKATAN (WBP) STUDI PENULISAN DI LEMBAGA PEMASYARAKATAN PEREMPUAN KELAS IIA DENPASAR
}

\author{
I Nyoma Suandika, SH,MH \\ I Gusti Ngurah Wirasatya
Fakultas Hukum, Universitas Mahendratta JI, Ken Arok N0. 10-12
Telp/Fax.0361 434827, Denpasar.E-mail:pakden278@gmail.com, ngurahwirasatya05@gmail.com

\begin{abstract}
ABSTRAK,Lembaga Pemasyarakatan merupakan tempat untuk melaksanakan pembinaan bagi para narapidana dan anak didik pemasyarakatan. Serta untuk mengetahui fungsi lembaga pemasyarakatan dalam melaksanakan pembinaan terhadap warga binaan pemasyarakatan (WBP) di Lembaga Pemasyarakatan Perempuan Kelas IIA Denpasar sesuai dengan Undang-Undang Nomor 12 Tahun 1995 Pasal (7) ayat (1) yaitu pembinaan dan pembimbingan warga binaan pemasyarakatan diselenggarakan oleh menteri dan dilaksanakan oleh petugas lapas. Dalam melaksanakan fungsi pembinaan terhadap warga binaan pemasyarakatan di Lembaga Pemasyarakatan Perempuan Kelas IIA Denpasar tentu memiliki kendala yang dihadapi oleh lembaga pemasyarakatan dan petugas pemasyarakatan itu sendiri. Upaya untuk melaksanakan fungsi pembinaan terhadap warga binaan pemasyarakatan di Lembaga Pemasyarakatan Perempuan Kelas IIA Denpasar.

Penelitian ini merupakan penelitian deskriptif dengan pendekatan kualitatif. Subjek penelitian ini adalah petugas pemasyarakatan. Objek penelitian ini adalah proses pembinaan yang dilakukan di Lembaga Pemasyarakatan Perempuan Kelas IIA Denpasas. Pengumpulan data dilakukan dengan metode observasi, wawancara, dan dokumentasi. Peneliti merupakan instrumen utama dalam melakukan penelitian yang dibantu oleh pedoman observasi, pedoman wawancara dan pedoman dokumentasi. Teknik yang digunakan dalam analisis data adalah display data, reduksi, dan penarikan kesimpulan.

Hasil penelitian menunjukkan bahwa proses lembaga pemasyarakatan dalam pembinaan narapidana di Lembaga Pemasyarakatan Perempuan Kelas IIA Denpasar berjalan dengan efektif sesuai dengan tujuan pemasyarakatan, faktor pendukung dalam pembinaan ini adalah keinginan warga binaan untuk menjadi lebih baik dari sebelumnya dan faktor penghambat dalam pembinaan adalah saran prasana kegiatan, keadaan di dalam lapas yang over kapasitas, jumlah petugas yang masih kurang, upaya yang dilakukan dalam memaksimalkan pembinaan warga binaan pemasyarakatan di Lembaga Pemasyarakatan Perempuan Kelas IIA Denpasar berkerjasama dengan pihak lain untuk membantu fungsi pembinaan di dalam lapas berjalan dengan baik.

Setelah dilakukan pembahasan dan penganalisaan, maka dapat disimpulkan bahwa Lembaga Pemasyarakatan Perempuan Kelas IIA Denpasar, sesuai dengan sistem Pemasyarakatan berdasarkan Undang-Undang Nomor 12 Tahun 1995
\end{abstract}


tentang Pemasyarakatan dan Peraturan Pemerintah Nomor 31 Tahun 1999 tentang Pembinaan dan Pembimbingan Warga Binaan Pemasyarakatan yang sudah berupaya membuat kerjasama seperti moU dengan pihak-pihak terkait sebagai contoh dengan pihak BLK IP Provinsi Bali dalam bidang menjahit, merajut kecantikan food processing, Pemerintah Daerah Kota Denpasar dalam bidang keagamaan, POLRI dalam bidang keamanan, IKIP PGRI Bali dalam pembinaan seni, budaya dan pendidikan.Yayasan Mercusuar dalam pembinaan bidang pelayanan ibu hamil dan bayi. BRI dalam pelayanan perbankan (e-money/BRIZZI).

Kata kunci: pembinaan, warga binaan pemasyarakatan, lembaga pemasyarakatan

ABSTRACT, Penitentiary is a place to implement development program for prisoners and correctional students. As well as to find out the function of correctional institutions in implementing development program of correctional citizens in Denpasar Women's Penitentiary Class IIA in accordance to Constitution Number 12 of 1995 Article 7 paragraph 1, namely developing and coaching correctional citizens held by the minister and implemented by prison officers. In developing the correctional citizens in prison at Denpasar Women's Penitentiary Class IIA, it found several obstacles by correctional institutions and correctional officers themselves.

This research was qualitative approach in form of descriptive study. The subjects of this study were correctional officers while the object of this research was the development process at the Denpasar Women's Penitentiary Class IIA. The data were collected from observation, interview, and documentation. Researcher was the main instrument in conducting research equipped with observation guidelines, interview guidelines and documentation guidelines. Techniques of data analysis was data display, reduction, and drawing conclusions.

The results showed that the process of correctional institutions in coaching prisoners in Denpasar Women's Penitentiary Class IIA was running effectively in accordance to the purpose of correcting. Supporting factors in this coaching were the desire of correctional citizens to improve. The inhibiting factors in coaching were the facilities to support activities, the overcapacity of prisons, and the lack of officers. In improving the quality of development program, Denpasar Women's Penitentiary Class IIA collaborates to other parties to run the coaching function well.

After the discussion and analysis, it can be concluded that Denpasar Women's Penitentiary Class IIA is in accordance to the Correctional System based on Constitution No 12 of 1995 concerning on Correctional Facilities and Government Regulation Number 31 of 1999 concerning Guidance and Development of Penitentiary Citizen which collaborating through $\mathrm{MoU}$ with related parties, for example BLK IP Bali in sectors of sewing, knitting, beauty, and food processing, Denpasar Government in the field of religion, POLRI in the field of security, IKIP PGRI Bali in fostering arts, culture and education, Mercusuar Foundation in developing services for pregnant women and infants, and BRI bank in banking services (e-money / BRIZZI).

Keywords: coaching, correctional citizens, institutions 


\section{Pendahuluan}

Lembaga Pemasyarakatan atau sering disebut LAPAS yaitu tempat untuk melaksanakan pembinaan warga binaan pemasyarakatan dan anak didik pemasyarakatan. Sebelum dikenal istilah lapas di Indonesia, tempat tersebut disebut dengan istilah penjara. Lembaga Pemasyarakatan merupakan Unit Pelaksana Teknis dibawah Direktorat Jenderal Pemasyarakatan Kementerian Hukum dan Hak Asasi Manusia dahulu (Departemen Kehakiman).

Seperti yang kita ketahui bersama dalam amanat Pasal (1) ayat (3) Undang-Undang Dasar 1945 ditegaskan bahwa Negara Indonesia adalah negara hukum. Oleh karena itu untuk menjalankan salah satu tujuan bernegara setiap warga Indonesia harus tertib hukum guna mencapai tujuan Negara Republik Indonesia yaitu untuk mewujudkan masyarakat yang adil dan makmur berdasarkan Pancasila.

Akhir-akhir ini sering diberitakan di sosial media ataupun di media-media cetak lainnya mengenai kejahatan kekerasan yang dilakukan sesama warga binaan pemasyarakatan di dalam lembaga pemasyarakatan. Hal ini mungkin disebabkan banyaknya faktor yang mempengaruhi, baik dari dalam maupun dari luar. Dengan kata lain dapatlah ditegaskan bahwa kegiatan pembinaan tidak mungkin dapat terselenggara tanpa didukung suasana aman dan tertib di dalam Unit Pelaksanaan Teknis (UPT) Pemasyarakatan.

Sistem pemasyarakatan

diselenggarakan dalam rangka membentuk Warga Binaan
Pemasyarakatan (WBP) agar menjadi manusia seutuhnya, menyadari kesalahan, memperbaiki diri dan tidak mengulangi tindak pidana sehingga dapat diterima kembali oleh lingkungan masyarakat, dapat aktif berperan dalam pembangunan, dan dapat hidup wajar sebagai warga yang baik dan bertanggungjawab.

Konsep pemasyarakatan pertama kali digagas oleh Menteri Kehakiman Sahardjo pada tahun 1962. Ia menyatakan bahwa tugas jawatan kepenjaraan bukan hanya melaksanakan hukuman, melainkan juga tugas yang jauh lebih berat adalah mengembalikan orangorang yang dijatuhi pidana ke dalam masyarakat

Program pembinaan inilah yang menarik minat penulis dalam membuat skripsi dengan judul "Fungsi Lembaga Pemasyarakatan dalam Melaksanakan Pembinaan terhadap Warga Binaan Pemasyarakatan (Studi Penulisan di Lembaga Pemasyarakatan Perempuan Kelas IIA Denpasar) “.

\section{Metode Penelitian}

Dalam penelitian ini menggunakan tipe penulisan lapangan-empiris yang ditunjang dengan bahan kepustakaan yaitu dengan melakukan penulisan terhadap bahan-bahan pustaka atau data-data sekunder yang selanjutnya dikaji untuk merumuskan hasil penulisan serta menarik kesimpulan dari permasalahan yang diteliti.

Dalam pengkajiannya dilakukan dengan metode pendekatan Statute Aprroach (Pendekatan Perundang-undangan) yaitu melihat 
maupun menelaah materi muatan dari aturan perundang-undangan yang berkaitan dengan isu hukum yang dibahas. Conceptual Approach (Pendekatan Konseptual) berupa bahan-bahan hukum dari literatur yang merupakan suatu proses menemukan prinsip-prinsip hukum maupun doktrin-doktrin hukum guna menjawab isu hukum yang dihadapi. Pendekatan kasus (Case Approach) dengan melakukan pengkajian terhadap kasus-kasus yang yang berkaitan dengan isu hukum yang dihadapi.

Sumber data didapat dari data primer, sekunder, data tersier, serta menggunakan metode kepustakaan berupa studi kepustakaan dan penulisan lapangan. Dalam pengumpulan data ini menggunakan metode interview, kuisioner, observasi, dan dokumenter.

Teknik pengolahan dan analisis data dilakukan secara kualitatif, hermeneutik, analisis isi dan deskriptif dengan menggambarkan dan menginterpretasikan data-data yang telah terkumpul sehingga diperoleh gambaran secara umum dan menyeluruh mengenai keadaan sebenarnya.

Penelitian dilakukan di Lembaga Pemasyarakatan Perempuan Kelas IIA Denpasar.

\section{Hasil dan Pembahasan}

A. Kendala dalam melaksanakan fungsi pembinaan di Lembaga Pemasyarakatan.

Dalam melaksanakan fungsi pembinaan terhadap warga binaan pemasyarakatan di Lembaga Pemasyarakatan Perempuan Kelas IIA Denpasar tentu memiliki kendala yang dihadapi oleh lembaga pemasyarakatan dan petugas pemasyarakatan itu sendiri, kendala yang dihadapi selama pembinaan Tahanan/Narapidana yaitu :

1. Terjadinya over kapasitas penghuni lapas.

2. Faktor Pendidikan yang berbedabeda terkadang membuat para petugas kewalahan dalam meyampaikan informasi yang ada.

3. Sarana Prasarana suatu hal yang menunjang berhasilnya pembinaan yang dilakukan.

4. Jumlah petugas yang masih kurang jika dibanding dengan jumlah narapidana tidak sebanding karena jumlah petugas Lembaga Pemasyarakatan Perempuan Kelas IIA Denpasar.

5. Pemasaran hasil keterampilan yang terbatas.

Fungsi pembinaan di dalam lembaga pemasyarakatan akan berjalan maksimal apabila semua unsur-unsur yang menopang atau yang mendukung terjadinya fungsi pembinaan didalam lapas terpenuhi, yang akan diharapakan narapidana yang sedang mejalankan masa pidananya dengan mengikuti pembinaan di Lembaga Pemasyarakatan diharapkan akan menjadi bekal saat bebas dan kembali ke lingkungan masyarakat.

\section{B. Upaya \\ Lembaga \\ Pemasyarakatan dalam melaksanakan fungsi pembinaan di Indonesia.}

Dalam pembinaan warga binaan pemasyarakatan yang dilakukan di Lembaga Pemasyarakatan Perempuan Kelas IIA Denpasar 
dalam pelaksanaannya tentunya ada kendala yang menghambat kegiatan pembinaan. Dengan jumlah warga binaan yang over kapasitas dan kurangnya sarana pendukung seperti latar belakang pendidikan warga binaan, sarana prasarana pendukung, jumlah petugas pemasyarakatan dan pemasaran hasil pembinaan yang masih kurang. Dari kendala yang diperoleh maka diperlukan upaya dalam mengatasi kendala tersebut. Binaan Pemasyarakatan memiliki rasa bersungguh-sungguh dalam mengikuti setiap pembinaan yang diberikan, dengan memberi reward/penghargaan apabila warga binaan pemasyarakatan mampu menjadi lebih baik dengan selalu mengikuti pembinaan yang diberikan, agar apa yang didapat di lembaga pemasyarakatan dapat menjadi bekal dikemudian hari. Dan menjalani kerjasama dengan pihak lain baik Lembaga Swadaya Masyarakat (LSM) dan dinas terkait untuk membantu pembinaan.

\section{Upaya Pembinaan Narapidana \\ Pada dasarnya pelaksanaan} pembinaan pemasyarakatan didasarkan atas prinsip-prinsip sistem pemasyarakatan untuk merawat, membina, mendidik dan membimbing warga binaan dengan tujuan agar menjadi warga yang baik dan berguna. Dalam proses pembinaan narapidana di lembaga pemasyarakatan dibutuhkan sarana dan prasarana pedukung guna mencapai keberhasilan yang ingin dicapai, yaitu: merupakan keadaan
a. Gedung pemasyarakatan penghuni di

dalamnya, karena hak-hak narapidana dilindungi oleh Undang-Undang Nomor 12 Tahun 1995, dimana dalam Pasal 14 Undang-Undang tersebut mengatur tentang hakhak yang dimiliki oleh narapidana. Adapun hak-hak tersebut menurut UndangUndang Nomor 12 Tahun 1995 yaitu:

a. Melakukan ibadah sesuai dengan agama atau kepercayaannya.

b. Mendapat perawatan, baik perawatan rohani maupun jasmani.

c. Mendapatkan pendidikan dan pengajaran.

d. Mendapatkan pelayanan kesehatan dan makanan yang layak.

e. Menyampaikan keluhan.

f. Mendapatkan bahan bacaan dan mengikuti siaran media massa lainnya yang tidak dilarang.

g. Mendapatkan upah atau premi atas pekerjaan yang dilakukan.

h. Menerima kunjungan keluarga, penasihat hukum, atau orang tertentu lainnya.

i. Mendapatkan pengurangan masa pidana (remisi).

j. Mendapatkan kesempatan berasimilasi termasuk cuti mengunjungi keluarga.

k. Mendapatkan pembebasan bersyarat.

1. Mendapatkan cuti menjelang bebas dan;

m. Mendapatkan hak-hak lain sesuai dengan peraturan perundang-undangan yang berlaku. 
b. Berkenaan dengan masalah petugas pelaksanaan pembinaan di lembaga pemasyarakatan ternyata dapat dikatakan belum sepenuhnya dapat menunjang tercapainya tujuan dari pembinaan itu sendiri mengingat jumlah petugas dan penghuni di Lembaga Pemasyarakatan Perempuan Kelas IIA

Denpasar tidaklah seimbang. Petugas pemasyarakatan sebagai abdi negara dan abdi masyarakat wajib menghayati serta mengamalkan tugas-tugas pembinaan pemasyarakatan dengan penuh tanggung jawab.

Ruang lingkup pembinaan bagi warga binaan pemasyarakatan dapat dibagi dalam dua bidang, yakni:

1. Pembinaan kepribadian
a. Pembinaan beragama
kesadaran
b. Pembinaan
kesadaran berbangsa dan bernegara
c. Pembinaan kemampuan intelektual
d. Pemninaan kesadaran hokum
e. Pembinaan mengintegrasikan diri dengan masyarakat

2. Pembinaan kemandirian
a. Keterampilan
untuk mendukung usaha-usaha mandiri, misalnya kerajinan tangan, industry rumah tangga, reparasi mesin dan alat- alat elektronika, dan sebagainya.
b. Keterampilan yang dikembangkan sesuai dengan bakatnya masing-masing.

$$
\text { Pelaksanaan wujud }
$$
pembinaan yang ada di lapas akan terasa berat apabila pihak lapas melaksanakan pembinaan sendiri. Untuk itu dalam melaksanakan pembinaan terhadap narapidana, pihak lapas bekerjasama dengan instansi-instansi yang lain dengan membuat MoU (Memorandum of Understanding) kesepakatan atau kesepahaman untuk membantu terwujudnya pelaksanaan kegiatan pembinaan atau keamanan di dalam lapas seperti:

Pertama membuat MoU (Memorandum of Understanding) dengan pihak Pemerintah Daerah Provinsi Bali dalam bidang kemandirian dengan BLK IP dalam bidang menjahit, merajut kecantikan food processing dimana bertujuan untuk menjalankan fungsi pembinaan bagi warga binaan pemasyarakatan yang diharapkan menambah pengetahuan dan akan menjadi bekal saat bebas dan kembali ke masyarakat. Saran dan prasarana yang diberikan seperti mesin jahit, gunting, benang dan kain.

Kedua membuat MoU (Memorandum of Understanding) dengan Pemerintah Daerah Kota Denpasar dalam bidang kepribadian dengan Kementerian Agama Kota Denpasar dalam bidang keagamaan (Islam, Hindu, Kristen, Katholilk, Budha) dengan adanya pembinaan keagamaan bagi warga binaan pemasyarakatan yang diharapkan warga binaan pemasyarakatan dapat menambah wawasan mengenai keagamaan.

Ketiga membuat $\mathrm{MoU}$ (Memorandum of Understanding) dengan POLRI dalam bidang kepribadian atau keamanan di lembaga pemasyarakatan dengan Babin Kantibmas yang dilakukan 
sambangan setiap hari ke lapas dengan adanya sambangan keamanan didalam dan didalam lapas tetap kondusif.

Keempat membuat $\mathrm{MoU}$ (Memorandum of Understanding) dengan tokoh masyarakat/yayasan dalam kepribadian dengan Yayasan Pertiwi dalam bidang pembinaan pendidikan dengan latar belakang pendidikan warga binaan yang berbagai macam maka upaya lapas dalam menjalankan fungsi pembinaan dengan berkerjasama dengan yayasan pertiwi ini diharapkak menambah pengetahuan warga binaan pemasyarakatan. Membuat $\mathrm{MoU}$ (Memorandum of Understanding) dengan IKIP PGRI Bali dalam bidang kepribadian dalam pembinaan seni, budaya dan pendidikan dengan adanya pembinaan seni, budaya diharapkan upaya fungsi pembinaan di lapas untuk menyalurkan minat dan bakat warga binaan pemasyarakatan dalam bidang seni dan kebudayaan. Membuat MoU dengan Yayasan Mercusuar dalam pembinaan kepribadian dalam bidang pelayanan ibu hamil dan bayi dengan adanya kerjasama dengan Yayasan Mercusuar diharapkan ibu hamil yang sedang menjalankan masa pidana di dalam lapas mendapat pelayan yang akan membuat psikis dan psikologis ibu dan bayi saat didalam lapas tidak memburuk akibat lingkungan lapas yang diisi oleh berbagai macam karakter yang mungkin bisa mengganggu perkembangan bayi. Sarana yang diberikan seperti pampers bayi, susu dan baju bayi.

Kelima membuat $\mathrm{MoU}$ (Memorandum of Understanding) dengan Bank Rakyat Indonesia (BRI) dalam pembinaan kepribadian dalam bidang pelayanan penggunakan produk dan jasa layanan perbankan (e-money/BRIZZI) dengan adanya kerjasama dengan BRI peredaran uang di dalam lapas dapat dimonitor untuk mencegah transaksi-transaksi ilegal di dalam lapas.

\section{Penutup}

\section{a. Simpulan}

Berdasarkan pokok permasalahan dan pembahasan mengenai model pembinaan narapidana di Lembaga Pemasyarakatan Perempuan Kelas IIA Denpasar, maka penulis akan menguraikan kesimpulan sebagai berikut:

1. Kendala yang dihadapi oleh Lembaga Pemasyarakatan Perempuan Kelas IIA Denpasar dalam melaksanakan fungsi pembinaan terhadap warga binaan pemasyarakatan seperti over kapasitas di dalam lapas, faktor latar belakang pendidikan warga binaan pemasyarakatan, sarana dan prasarana kegiatan pembinaan, jumlah petugas yang tidak seimbang dengan jumlah warga binaan, pemasaran hasil keterampilan yang terbatas.

2. Upaya yang dilakukan oleh lembaga pemasyarakatan untuk melaksanakan fungsi pembinaan terhadap warga binaan pemasyarakatan di Lembaga Pemasyarakatan Perempuan Kelas IIA Denpasar, upaya pembinaan yang dilakukan di Lembaga Pemasyarakatan Perempuan 
Kelas IIA Denpasar dilaksanakan dengan sistem Pemasyarakatan berdasarkan Undang-Undang Nomor 12 Tahun 1995 tentang Pemasyarakatan. Pelaksanaan pembinaan narapidana berdasarkan Peraturan Pemerintah Nomor 31 Tahun 1999 tentang Pembinaan dan Pembimbingan Warga Binaan Pemasyarakatan, dimana tujuan pembinaan adalah untuk membentuk warga binaan pemasyarakatan agar menjadi manusia seutuhnya, menyadari kesalahannya, memeperbaiki diri, dan tidak mengulangi tindak pidananya lagi, sehingga dapat diterima kembali oleh lingkungan masyarakat. Pembinaan narapidana di Lembaga Pemasyarakatan Perempuan Kelas IIA Denpasar dilaksanakan dalam bentuk pembinaan kepribadian dan pembinaan kemandirian sebagaimana yang diatur dalam Pasal (2) Peraturan Pemerintah Nomorr 31 Tahun 1999 tentang Pembinaan dan Pembimbingan Warga Binaan. Dengan menggandeng dinas terkait untuk membantu upaya menjalankan fungsi pembinaan bagi warga binaan di dalam lapas.

\section{a. Saran}

Berdasarkan pada permasalahan yang diangkat oleh penulis yaitu mengenai Pembinaan Hukum Di Lembaga Pemasyarakatan Perempuan Kelas IIA Denpasar, maka dari itu penulis memberikan saran sebagai berikut:

1. Pemerintah meningkatkan sarana dan prasarana pada lembaga pemasyarakatan, agar tidak terjadi lagi kelebihan kapasitas contohnya pada Lembaga Pemasyarakatan

Perempuan Kelas IIA Denpasar, serta perlu adanya peningkatan kualitas petugas pemasyarakatan seperti penambahan jumlah petugas pemasyarakatan untuk bejaga didalam blok hunian, karena tidak sesuai dengan jumlah narapidana di dalam Lapas.

2. Lembaga pemasyarakatan agar meningkatkan sumber daya manusia bagi para petugas pemasyarakatan dan warga binaan dengan berbagai macam pelatihanpelatihan.

3. Masyarakat diharapkan yang berada di luar lapas dapat membantu berjalannya program pembinaan di Lembaga Pemasyarakatan Perempuan Kelas IIA Denpasar, dengan cara turut serta mematuhi peraturanperaturan yang ada ketika berkunjung ke dalam Lapas, dan tidak membawakan narapidana barang-barang terlarang.

\section{Daftar pustaka Buku:}

Bisri.Ilhami. 2004, Sisitem 
Hukum Indonesia. PT Raja Grafindo Persada, Jakarta.

Brouwer.J.G. dan Schilder. 1988.

A Survey of Dutch Administrative Law.

Nijmegen: Ars Aeguilibri.

Fuady.Munir. 2009. Teori Negara

Hukum Modern

(Rehctstaat). Bandung:

Refika Aditama

Helmi.Masdar. 1973. Dakwah

Dalam Alam

Pembangunan. Jakarta:

Balai Pustaka.

Kusnardi.Moh. dan

Ibrahim.Harmaily. 1988.

Hukum Tata Negara

Indonesia. Jakarta: Sinar

Bakti.

Lamintang.P.A.F. dan

Lamintang. Theo. 2010.

Hukum Penitensir

Indonesia. Jakarta: Sinar

Grafika.

Marzuki.Peter Mahmud. 2014. Penelitian Hukum.

Jakarta: Cetakan ke Sembilan, Kencana.

Muladi. 1997. Hak Asasi Manusia, Politik, dan Sistem Peradilan Pidana, Pembinaan Narapidana di Lembaga Pemasyarakatan Nusa Kambangan, Semarang: Badan Penerbit Universitas Diponegoro.

Panajaitan.Petrus irwan. 1996. upaya pembaharuan pemikiran $d r$. sahardjo mengenai pemasyrakatan sebagai tujuan pidana penjara. Jakarta: Universitas Indonesia.

Pasaribu.Simanjuntak, B., I. L. 1990. Membina dan
Mengembangkan

Generasi Muda. Bndung.

Poernomo.Bambang. 1986.

Pelaksanaan Pidana

Penjara dengan Sistem

Pemasyarakatan.

Yogyakarta: liberty.

Priyatno.Dwidja. 2006. Sistem

Pelaksanaan Pidana

Penjara di Indonesia.

Bandung: Refika

Admitama

Rivai.Andi Wijaya. 2014. Buku

Pintar Pemasyarakatan.

Cetakan Pertama.

Lembaga Kajian

Pemasyarakatan. Jakarta.

Stroink.F.A.M. dalam

Thalib.Abdul Rasyid.

$2006 . \quad$ Wewenang

Mahkamah Konstitusi dan

Aplikasinya dalam Sistem

Ketatanegaraan Republik

Indonesia. Bandung: Citra

Aditya Bakti.

Sujatno.Adi. 2000. Negara Tanpa

Penjara (Sebuah

Renungan). Jakarta:

Direktor Jenderal

Pemasyarakatan.

Supramono.Gatot. 2007. Hukum Acara Pengadilan Anak. Jakarta: Intan Sejati.

Peraturan

undangan:

perundang-

Undang-Undang Dasar Negara

Republik Indonesia Tahun 1945.

Undang-Undang Nomor 12 Tahun 1995 Tentang

Pemasyarakatan. Lembaran

Negara Tahun 1995 Nomor

77, Tambahan Lembaran

Negara Nomor 3641.

Peraturan Pemerintah Nomor 31

Tahun 1999 Tentang 
Pembinaan dan

Pembimbingan Warga

Binaan Pemasyarakatan.

Peraturan Pemerintah Nomor 32

tahun 1999 Tentang

Syarat Dan Tatacara

Pelaksanaan Hak Waga

Binaan Pemasyarakatan.

Peraturan Pemerintah Nomor 57

Tahun 1999 Tentang

Kerjasama

Penyelenggaraan

Pembinaan dan Direktorat

Jenderal Pemasyarakatan

Departemen Hukum dan

Hak Asasi Manusia

Republik Indonesia Tahun

2009, Pembaharuan

Pelaksanaan Sistem

Pemasyarakatan.

Keputusan Menteri Kehakiman

Nomor.M.02-PK.04.10,

Tentang Pola Pembinaan

Narapidana/Tahanan.

Pembimbingan Warga

Binaan Pemasyarakatan.

\section{Internet:}

Kamus Besar Bahasa Indonesia,

Narapidana.

https://kbbi.web.id.

Diakses pada 19 Mei

2020, pukul 21.45.

www.hukumonline.com, Esensi

Lemabaga

Pemasyarakatan sebagai wadah pembinaan

narapidana, 24 Mei 2020, pukul 12.28.

Kamus Besar Bahasa Indonesia, Narapidana.

https://kbbi.web.id.

Diakses pada 19 Mei

2020, pukul 21.45.

Kamus Besar Bahasa Indonesia,

Narapidana.

https://kbbi.web.id.
Diakses pada 19 Mei

2020, pukul 21.45. 
Raad Kertha, Vol. 04, No. 01 Pebruari 2021 - Juli 2021 